\title{
Silencing of Twist1 sensitizes NSCLC cells to cisplatin via AMPK-activated mTOR inhibition
}

\author{
H-O Jin ${ }^{\star, 1}$, S-E Hong ${ }^{1,2}$, S-H Woo ${ }^{1}$, J-H Lee ${ }^{3}$, T-B Choe ${ }^{4}$, E-K Kim ${ }^{5}$, W-C Noh ${ }^{5}$, J-K Lee ${ }^{6}$, S-I Hong ${ }^{1,6}$, J-I Kim² and I-C Park
}

Twist1 is highly expressed in primary and metastatic non-small cell lung cancer (NSCLC), and thus acts as a critical target for lung cancer chemotherapy. In the current study, we investigated the underlying mechanism initiated by silencing of Twist 1 that sensitizes NSCLC cells to cisplatin. Silencing of Twist1 triggered ATP depletion, leading to AMP-activated protein kinase (AMPK)-activated mammalian target of rapamycin (mTOR) inhibition in NSCLC cells. AMPK-induced mTOR inhibition, in turn, resulted in downregulation of ribosome protein S6 kinase 1 (S6K1) activity. Downregulation of mTOR/S6K1 reduced Mcl-1 protein expression, consequently promoting sensitization to cisplatin. Overexpression of Mcl-1 reduced PARP cleavage induced by cisplatin and Twist1 siRNA, suggesting that this sensitization is controlled through Mcl-1 expression. Interestingly, cells treated

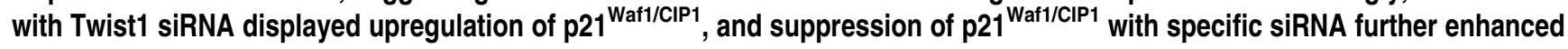
the cell death response to cisplatin/Twist1 siRNA. In conclusion, silencing of Twist1 sensitizes lung cancer cells to cisplatin via stimulating AMPK-induced mTOR inhibition, leading to a reduction in Mcl-1 protein. To our knowledge, this is the first report to provide a rationale for the implication of cross-linking between Twist1 and mTOR signaling in resistance of NSCLC to anticancer drugs.

Cell Death and Disease (2012) 3, e319; doi:10.1038/cddis.2012.63; published online 7 June 2012

Subject Category: Cancer

Lung cancer remains the leading cause of cancer-related death worldwide. About $80 \%$ of all lung cancers are non-small cell lung cancer (NSCLC), including squamous carcinoma, adenocarcinoma and large cell carcinoma, with $>50 \%$ of these patients presenting with locally advanced or metastatic disease. ${ }^{1}$ The 5 -year survival rates for advanced NSCLC are only $10-20 \%$, partly due to advanced metastasis. ${ }^{2}$ Cisplatin is a commonly used therapeutic agent for advanced NSCLC. However, resistance to cisplatin is a major obstacle in potentially curative treatments for advanced NSCLC. ${ }^{3}$

The mammalian target of rapamycin (mTOR) is a highly conserved serine/threonine kinase that regulates cell growth, cell cycle progression and metabolism. The phosphatidylinositol-3 kinase/AKT signaling pathway activates mTOR, in turn, directly phosphorylating ribosome protein S6 kinase 1 (S6K1) and eIF4E-binding protein 1, both of which are important in the control of protein translation initiation. ${ }^{4-6}$ S6K1 phosphorylates S6, which regulates the translation of $5^{\prime}$ terminal oligopyrimidine mRNAs that encode ribosomal proteins and translation factors. 4EBP1 binds to and prevents elF4E, initiating cap-dependent translation. mTOR is constitutively activated in a variety of human cancers, including ovarian, pancreatic, as well as lung carcinoma. ${ }^{7}$ Thus, mTOR signaling networks have emerged as attractive targets in novel therapeutic anticancer strategies.

Epithelial-to-mesenchymal transition (EMT) is a fundamental biological process by which epithelial cells are converted to mesenchymal cells during embryonic development. This process is characterized by loss of cell polarity, decrease in cell-cell adhesion and gain in migration ability. Recently, the concept of EMT has been extended to tumor migration, invasion and metastasis. ${ }^{8,9}$ The EMT process is controlled by zinc-finger proteins (Snail, Slug, Zeb1 and Zebs/SIP1) and basic helix-loop-helix factors (Twist and E47). ${ }^{10}$

Twist is an important inducer of EMT, which downregulates the epithelial cell marker (E-cadherin) and upregulates mesenchymal markers (fibronectin, $\mathrm{N}$-cadherin and vimentin), and promotes cancer invasion and metastasis. ${ }^{11,12}$ Twist expression promotes resistance to apoptosis when cells are challenged with cisplatin in lung and bladder cancer and paclitaxel in prostate cancer. ${ }^{13}$ Accordingly, identification of the upstream activators and downstream targets of Twist1

\footnotetext{
${ }^{1}$ Division of Radiation Cancer Research, Korea Institute of Radiological and Medical Sciences, 215-4 Gongneung-dong, Nowon-gu, Seoul 139-706, Republic of Korea; 2Department of Food and Microbial Technology, Seoul Women's University, 126 Gongneung-dong, Nowon-gu, Seoul 139-774, Republic of Korea; ${ }^{3}$ Laboratory of Molecular Oncology, Cheil General Hospital and Women's Healthcare Center, Kwandong University, College of Medicine, 1-19 Mukjeong-dong, Jung-gu, Seoul 100-380, Republic of Korea; ${ }^{4}$ Department of Microbiological Engineering, Kon-Kuk University, 120 Hwayang-dong, Gwangjin-gu, Seoul 143-701, Republic of Korea; ${ }^{5}$ Department of Surgery, Korea Cancer Center Hospital, Korea Institute of Radiological and Medical Sciences, 215-4 Gongneung-dong, Nowon-gu, Seoul 139-706, Republic of Korea and ${ }^{6}$ Department of Laboratory Medicine, Korea Cancer Center Hospital, Korea Institute of Radiological and Medical Science, 215-4 Gongneungdong, Nowon-gu, Seoul 139-709, Republic of Korea

${ }^{*}$ Corresponding authors: H-O Jin or I-C Park, Division of Radiation Cancer Research, Korea Institute of Radiological and Medical Sciences, 215-4 Gongneung-dong, Nowon-gu, Seoul 139-706, Republic of Korea. Tel: +82 2970 1378; Fax: +82 2970 2402; E-mail: hyeonok@kirams.re.kr (HOJ) or parkic@kirams.re.kr (ICP) Keywords: AMPK; cisplatin; mTOR; p21 $1^{\text {Waf1/CIP1; }}$ Twist1

Abbreviations: AMPK, AMP-activated protein kinase; EMT, epithelial-to-mesenchymal transition; mTOR, mammalian target of rapamycin; MTT, 3-(4,5dimethylthiazolyl-2)-2,5-diphenyltetrazolium bromide; NSCLC, non-small cell lung cancer; S6K1, ribosome protein S6 kinase 1

Received 02.4.12; revised 30.4.12; accepted 07.5.12; Edited by G Raschellà
} 
may be critical in determining new therapeutic targets for cancer. In the present study, we showed that knockdown of Twist promotes or sensitizes lung cancer cells to apoptotic death via decreasing mTOR/S6K1-dependent Mcl-1 translation that allows cisplatin to exert its toxic effect. These results suggest that targeting molecular cross-talk between mTOR and EMT regulators may be an effective approach to combat cancer.

\section{Results}

Knockdown of Twist 1 enhances cisplatin-induced cell death in NSCLC. Twist1 is highly expressed in primary and metastatic NSCLC, ${ }^{14}$ and therefore an attractive therapeutic target for lung cancer. Initially, we investigated whether downregulation of Twist1 enhances cisplatin sensitivity in NSCLC cells. Two lung cancer cell lines, A549 and H1299, expressed high levels of Twist1 (Figure 1b), consistent with previous reports. ${ }^{14}$ A549 and $\mathrm{H} 1299$ cells were transfected with Twist1 siRNA and exposed to cisplatin at doses of 8 and $6 \mu \mathrm{M}$ for $24 \mathrm{~h}$, respectively. At these concentrations of cisplatin, the growth inhibitory effects $<20 \%$ (Figure 1a). The two Twist 1 siRNAs led to a considerable knockdown of mRNA expression in both cell types (Figure 1b). Twist1 suppression with siRNAs induced a sensitization effect to cisplatin (Figure 1c) and enhanced PARP cleavage (Figure 1d). Our results clearly indicate that suppression of Twist 1 effectively enhances the sensitivity of NSCLC cells to cisplatin.

Knockdown of Twist1 enhances cell sensitivity to cisplatin through Mcl-1 downregulation. Next, we determined the effect of Twist1 knockdown on clonogenic survival. As shown in Figure $2 a$, colony formation was significantly reduced in cells transfected with Twist1 siRNA, compared with control siRNA. Silencing Twist1 expression with siRNA had no effect on the expression of EMT-related proteins,

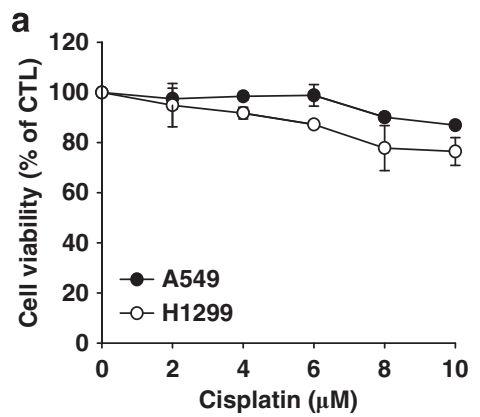

b
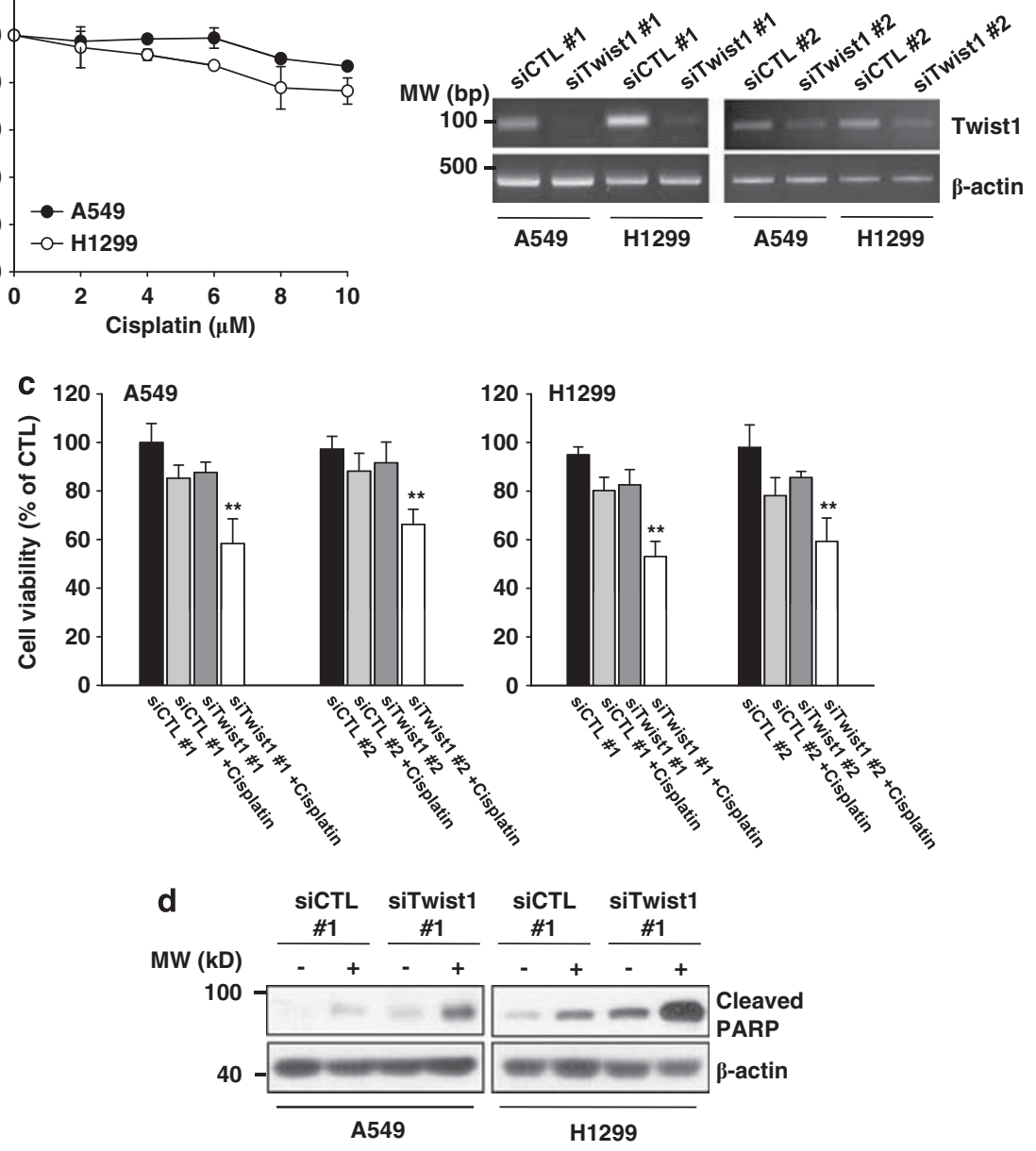

Figure 1 Knockdown of Twist1 enhances NSCLC cell sensitivity to cisplatin. (a) A549 and H1299 cells were treated with the indicated concentrations of cisplatin for $24 \mathrm{~h}$. Cell viability was measured with the MTT assay. The viability of control cells was set at $100 \%$, and survival relative to the control presented. (b) A549 and H1299 cells were transfected with two different Twist 1 or control siRNAs for $30 \mathrm{~h}$. Twist $1 \mathrm{mRNA}$ levels were measured using RT-PCR analysis. (c and d) A549 and H1299 cells were transfected with siCTL or siTwist 1 for $20 \mathrm{~h}$, followed by 8 (A549 cells) or $6 \mu \mathrm{M}$ (H1299 cells) cisplatin for $24 \mathrm{~h}$. Cell viability was measured with the MTT assay (c) and protein levels determined using western blot analysis (d). Data shown are representative of three independent experiments. All graphs are shown as the mean of each group and error bars represent S.D. ${ }^{* \star} P<0.01$ versus the siCTL/cisplatin-treated group or siTwist1-treated group 
a

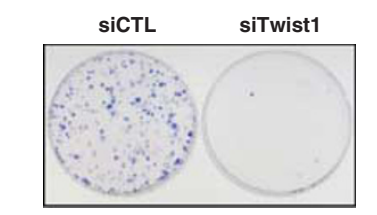

C

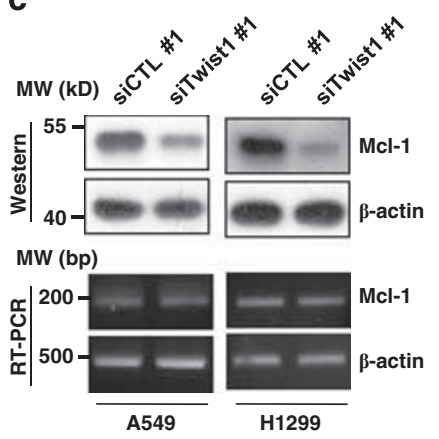

b

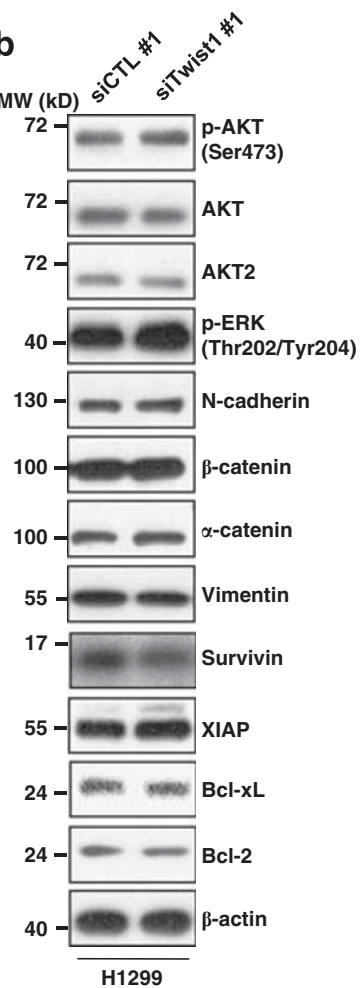

Figure 2 Knockdown of Twist 1 induces a decrease in Mcl-1 protein expression. (a) H1299 cells were transfected with control or Twist 1 siRNA for $24 \mathrm{~h}$. Cells were reseeded at a density of 2000 cells per well in three $60-\mathrm{mm}$ plates. Colony formation was monitored over the following 10 days. Colonies were stained using the Diff-Quick kit. (b and c) A549 and H1299 cells were transfected with control or Twist1 siRNA for $30 \mathrm{~h}$. The indicated protein and $\mathrm{mRNA}$ levels were measured using western blot ( $b$ and $\mathbf{c}$ ) and RT-PCR (c) analyses. Data shown are representative of at least two independent experiments

such as $\mathrm{N}$-cadherin, $\alpha$-catenin, $\beta$-catenin and vimentin (Figure 2b), suggesting that chemosensitivity induced by Twist1 downregulation is not related to EMT-related protein expression. Recent studies showed that activation of AKT (especially AKT2) by Twist1 is critical for the maintenance of EMT and promotion of invasion ${ }^{15,16}$ and activation of the ERK pathway by EGF has profound feedback on EGFR signaling, which activates EMT via the AKT pathway. ${ }^{17} \mathrm{We}$ then investigated the effect of AKT and ERK activation in cells with Twist 1 siRNA. Silencing of Twist1 did not affect the AKT and ERK activation, as assessed by the protein level of p-AKT, p-ERK, AKT and AKT2 (Figure 2b). However, expression of $\mathrm{Mcl}-1$ protein was markedly decreased in cells treated with Twist1 siRNA, compared with other $\mathrm{Bcl}-2$ members, such as $\mathrm{Bcl}-\mathrm{xL}$ and $\mathrm{Bcl}-2$ (Figures $2 \mathrm{~b}$ and $\mathrm{c}$ ). The survivin protein, unlike IAP family member, such as XIAP, was also found to be slightly decreased in the presence of Twist1 siRNA. Notably, downregulation of survivin by Twist 1 siRNA did not confer sensitivity to cisplatin (data not shown). To understand how Mcl-1 downregulation occurs in cells treated with Twist1 siRNA, we analyzed Mcl-1 mRNA expression using RT-PCR. No significant differences were detected among both cell types treated with control and Twist1 siRNA (Figure 2c), excluding the possibility of transcriptional regulation.

A recent study reported that NSCLC cell lines express high levels of $\mathrm{Mcl}-1$, and suppression of $\mathrm{Mcl}-1$ induces significant cell death. ${ }^{18}$ As expected, downregulation of $\mathrm{Mcl}-1$ with siRNA induced cell death and PARP protein cleavage in our experiments (Figures $3 a$ and $b$ ). Colony formation was also reduced in the presence of Mcl-1 siRNA, compared with control siRNA (Figure 3c). To further establish whether $\mathrm{Mcl}-1$ has an essential role in NSCLC survival, we transfected Histagged Mcl-1 plasmids in cells treated with Twist 1 siRNA and cisplatin. Twist1 siRNA or/and cisplatin-induced PARP cleavage was reduced upon overexpression of $\mathrm{Mcl}-1$ (Figure 3d). Our data indicate that downregulation of $\mathrm{Mcl}-1$ is critical for the sensitizing effect of Twist1 siRNA on cisplatininduced cell death.

Knockdown of Twist1 leads to inhibition of mTOR activity, which has an important role in Mcl-1 downregulation. Next, we investigated the mechanism by which knockdown of Twist1 suppresses $\mathrm{Mcl}-1$ protein expression. Initially, mTOR activity was assessed in cells treated with Twist1 siRNA. Twist1 siRNA induced suppression of mTOR activity, as assessed based on the decrease in phosphorylation of mTOR and the mTOR effectors, S6K and S6, in H1299 cells (Figure $4 \mathrm{a}$ ). A recent report showed that mTOR promotes survival through translational control of $\mathrm{Mcl}-1 .{ }^{19}$ Accordingly, we analyzed the Mcl-1 protein level in cells treated with mTOR siRNA. As expected, suppression of mTOR resulted in decreased expression of $\mathrm{Mcl}-1$ protein and enhanced $\mathrm{H} 1299$ cell sensitivity to cisplatin (Figures $4 b$ and $c$ ).

S6K1, a downstream target of mTOR, has important roles in cell proliferation, protein translation and cell survival and is thus an effective target for cancer therapy. ${ }^{20}$ To ascertain whether S6K1 is involved in the regulation of $\mathrm{Mcl}-1$ expression and consequent cell survival, we transfected cells with S6K1 siRNA, followed by treatment with cisplatin. S6K1 siRNA induced a decrease in Mcl-1 protein, relative to control siRNA (Figure 5a). Moreover, knockdown of S6K1 enhanced cisplatin-induced cell death (Figures $5 b$ and $c$ ). Overexpression of S6K1 reduced PARP cleavage induced by Twist1 siRNA (Figure 5d). Based on these results, we propose that mTOR activity is suppressed upon Twist 1 knockdown, which is critical for Mcl-1 downregulation.

Knockdown of Twist1 leads to inhibition of mTOR activity through AMP-activated protein kinase (AMPK) activation. mTOR activity is suppressed under conditions of energy deprivation in which depleted ATP levels trigger AMPK activation. ${ }^{21}$ We further investigated whether AMPK is involved in mTOR inhibition induced by Twist1 suppression. As shown in Figure 6b, treatment with Twist1 siRNA stimulated phosphorylation of AMPK and the AMPK substrate, acetyl-CoA carboxylase, in A549 and H1299 cells. Moreover, suppression of Twist1 led to a marked increase in the cellular ADP/ATP ratio, indicating a decrease in the ATP content in both cell types (Figure 6a). To establish the involvement of AMPK in Twist1 siRNA-induced mTOR inhibition, we transfected cells displaying Twist1 downregulation with $\mathrm{AMPK} \alpha 1 / 2$ siRNA. Downregulation of AMPK led to recovery of mTOR activity inhibited by Twist 1 siRNA (Figure 6c). Our results collectively suggest that silencing of 

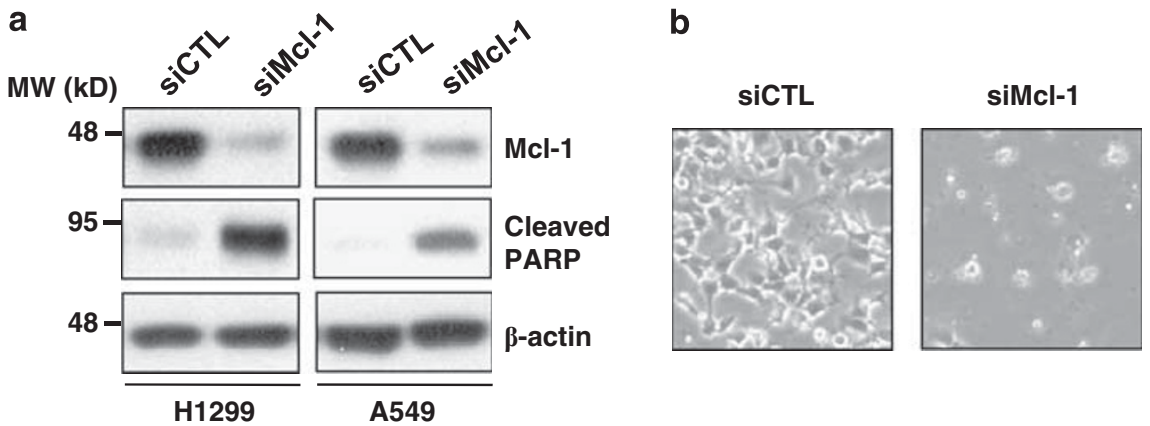

C

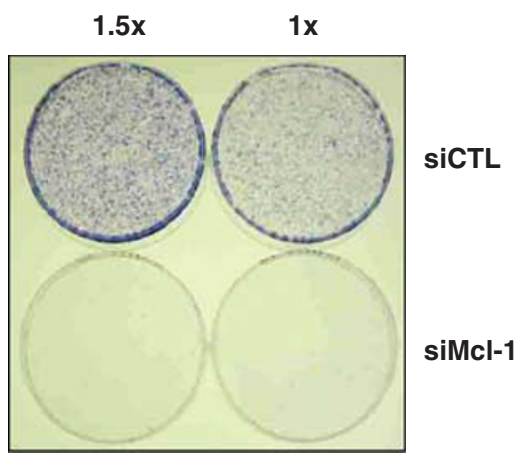

d

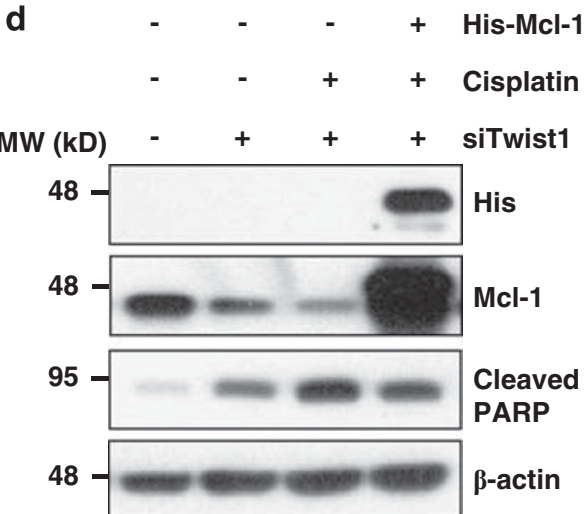

Figure $3 \mathrm{Mcl}-1$ is essential for NSCLC survival. (a and $\mathbf{b})$ A549 and $\mathrm{H} 1299$ cells were transfected with control or Mcl-1 siRNA for $48 \mathrm{~h}$. Cell morphology images were obtained under a microscope (b). (c) H1299 cells were transfected with control or Mcl-1 siRNA for $24 \mathrm{~h}$. Cells were reseeded at a density of $2000(1 \times)$ and $3000(1.5 \times)$ cells per well in three 60-mm plates. Colony formation was monitored over the following 10 days. Colonies were stained using the Diff-Quick kit. (d) H1299 cells were transfected with plasmids for empty vector control (pcDNA3) or His-tagged Mcl-1 (His-Mcl-1) or control or Twist1 siRNAs for $24 \mathrm{~h}$, followed by treatment with $5 \mu \mathrm{M}$ cisplatin for $24 \mathrm{~h}$. The indicated protein levels were measured using western blot analysis (a and $\mathbf{d})$. In all panels, representative of three independent experiments is shown
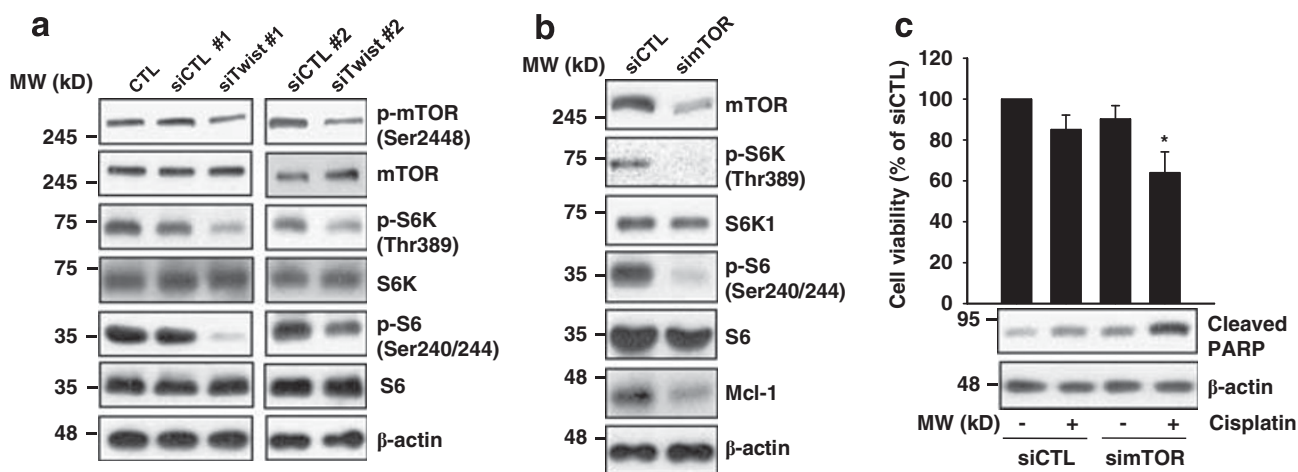

Figure 4 Knockdown of Twist1 knockdown inhibits mTOR-mediated Mcl-1 downregulation. (a) H1299 cells were transfected with two different Twist1 or control siRNAs for $30 \mathrm{~h}$. (b) H1299 cells were transfected with control or mTOR siRNA for $30 \mathrm{~h}$. (c) H1299 cells were transfected with control or mTOR siRNA for $20 \mathrm{~h}$, followed by treatment with $5 \mu \mathrm{M}$ cisplatin for $24 \mathrm{~h}$. Cell viability was measured with the MTT assay (c). The viability of control siRNA (siCTL)-treated group was set at $100 \%$, and survival relative to the siCTL presented. The indicated protein levels were measured using western blot analysis $(\mathbf{a}-\mathbf{c})$. The blot shown is representative of two independent experiments. Cell viability data are shown as the mean of triplicate samples, and error bars reflect S.D. ${ }^{*} P<0.05$ versus the siCTL/cisplatin-treated group or simTOR-treated group

Twist1 expression is associated with ATP depletion, leading to AMPK-activated mTOR inhibition.

p21 ${ }^{\text {Waf1/CIP1 }}$ downregulation triggers the cell death to Twist1 siRNA and cisplatin. In view of the earlier finding that increased $\mathrm{p} 21^{\mathrm{Waf} 1 / \mathrm{ClP} 1}$ expression determines cisplatin resistance in human testicular cancer, ${ }^{22}$ we analyzed the p21 Waf1/CIP1 $\mathrm{mRNA}$ and protein levels in NSCLC cells treated with cisplatin. As shown in Figures $7 \mathrm{a}$ and $\mathrm{b}$, cisplatin induced an increase in the $\mathrm{p} 21^{\mathrm{Waf} 1 / \mathrm{CIP} 1} \mathrm{mRNA}$ and protein levels in a dose-dependent manner. p21 ${ }^{\text {Waf1/CIP1 }}$ upregulation by cisplatin was observed, even in p53-defective H1299 cells, suggesting that cisplatin induces p21 expression in a p53-independent manner. Interestingly, p21 $1^{\mathrm{Waf} 1 / \mathrm{CIP} 1}$ was additionally upregulated by Twist 1 siRNA in both cell types, as shown in Figure 7c. We further investigated whether p21 $1^{\text {Waf1/CIP1 }}$ has a protective role against cisplatin and/or Twist1 knockdown-induced cell death by transfecting cells 
a

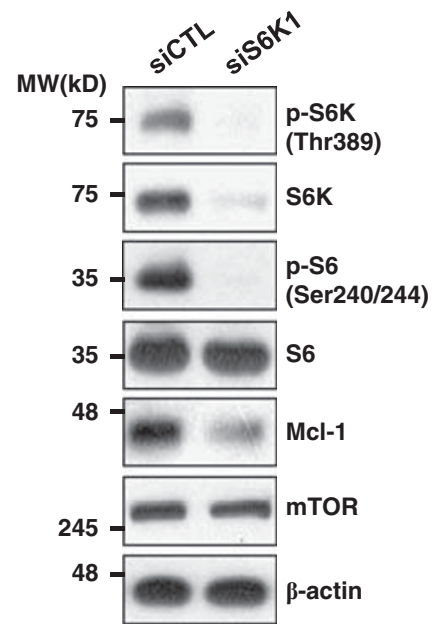

C

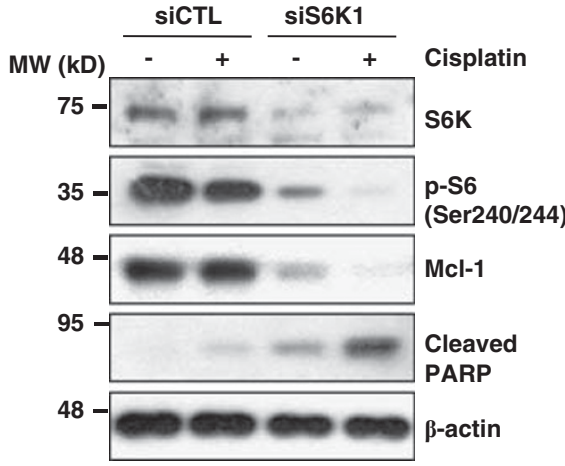

b

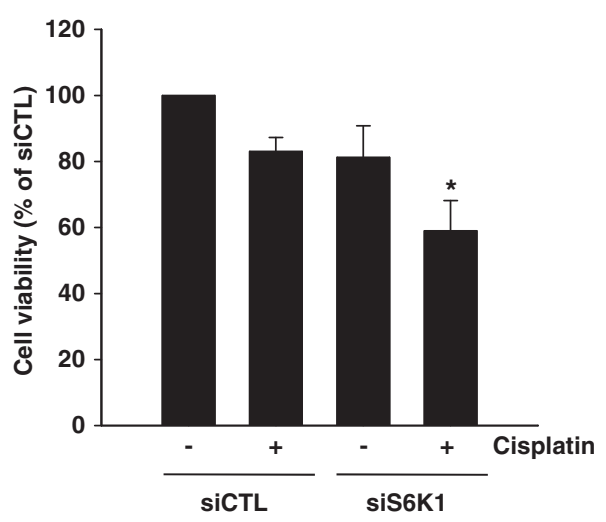

d

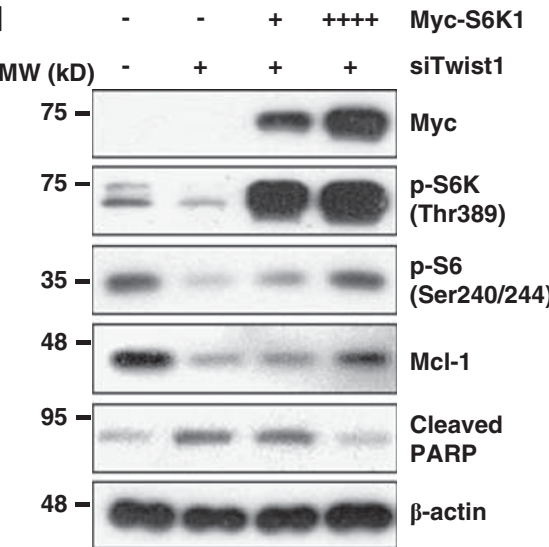

Figure 5 Twist1 knockdown-induced Mcl-1 decrease is mediated by S6K1 downregulation. (a) H1299 cells were transfected with control or S6K1 siRNA for $30 \mathrm{~h}$. (b and c) $\mathrm{H} 1299$ cells were transfected with control or S6K1 siRNA for $20 \mathrm{~h}$, followed by treatment with $5 \mu \mathrm{M}$ cisplatin for $24 \mathrm{~h}$. Cell viability of control siRNA (siCTL)-treated group was set at $100 \%$, and survival relative to the siCTL presented (b). (d) $\mathrm{H} 1299$ cells were transfected with increasing concentrations of Myc-tagged S6K1, along with Twist1 siRNA for $48 \mathrm{~h}$. The indicated protein levels were measured using western blot analysis $(\mathbf{a}, \mathbf{c}$ and $\mathbf{d})$. Data shown are representative of at least two independent experiments. Cell viability data are shown as the mean of each group and error bars reflect S.D. ${ }^{\star} P<0.05$ versus the siCTL/cisplatin-treated group or siS6K1-treated group

administered with cisplatin and/or Twist1 siRNA with $\mathrm{p} 21^{\text {Waf1/CIP1 }}$ siRNA. p21 $1^{\text {Waf } 1 / \mathrm{CIP} 1}$ depletion resulted in enhanced sensitivity of cells to Twist 1 siRNA and cisplatin-mediated apoptosis (Figure $7 d$ ), suggesting a role of $\mathrm{p} 21^{\text {Waf1/CIP1 }}$ in preventing cell death by cisplatin or Twist1 siRNA in NSCLC.

\section{Discussion}

In the present study, we demonstrated that: (1) knockdown of Twist 1 enhances cisplatin-induced cell death in NSCLC cells, (2) antiapoptotic $\mathrm{Mcl}-1$ is significantly downregulated upon knockdown of Twist1, (3) mTOR activity is suppressed upon Twist1 knockdown, which has an important role in Mcl-1 downregulation, (4) ATP depletion and AMPK activation induced by Twist1 siRNA induces mTOR suppression, (5) $\mathrm{p} 21^{\text {Waf1/Cip } 1}$ is upregulated in cells treated with cisplatin and/or siRNA targeting Twist1 and (6) suppression of p21Waf1/ CIP1 potentiates cell death induced by cisplatin and/or Twist1 siRNA. To our knowledge, this is the first report to show that cross-talk between EMT regulators and mTOR signaling is implicated in resistance to anticancer drugs in NSCLC.
Cisplatin is an effective anticancer drug widely used to treat various solid tumors, including NSCLC. However, acquirement of resistance is a primary impediment in cancer treatment. ${ }^{3}$ Knockdown of Twist 1 with specific siRNA sensitized A549 and H1299 NSCLC cells to cisplatin-induced cell death. Our data are consistent with previous study, suggesting that Twist depletion increases A549 cell sensitivity to cisplatin. ${ }^{23}$ This sensitizing effect was independent of the p53 status, because efficient sensitization was observed in p53defective $\mathrm{H} 1299$ cells. Mcl-1 protein expression was markedly decreased in cells treated with Twist 1 siRNA, compared with other $\mathrm{Bcl}-2$ members (Figure $2 \mathrm{~b}$ ). Overexpression of $\mathrm{Mcl}-1$ suppressed cell death induced by the Twist1 siRNA and cisplatin combination. These results indicate that downregulation of $\mathrm{Mcl}-1$ has an important role in the sensitizing effect of Twist 1 siRNA on cisplatin-induced cell death. Indeed, $\mathrm{Mcl}-1$ has been shown to be a critical survival factor in multiple myeloma as well as NSCLC. ${ }^{18} \mathrm{Mcl}-1$ is a highly unstable protein, requiring active protein synthesis to maintain its expression levels. ${ }^{24}$ In our experiments, knockdown of Twist 1 reduced $\mathrm{Mcl}-1$ protein, but not mRNA levels (Figure 2c). 


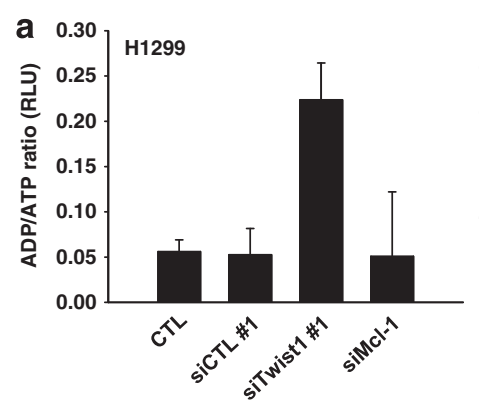

b

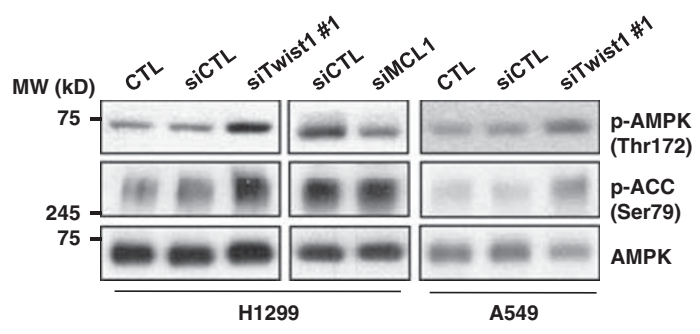

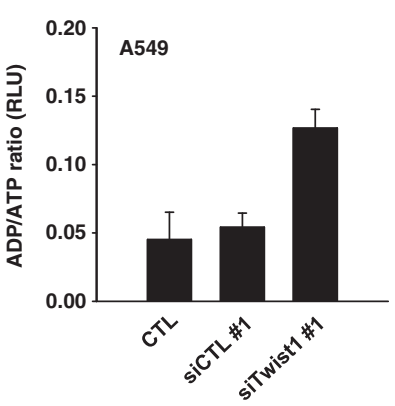

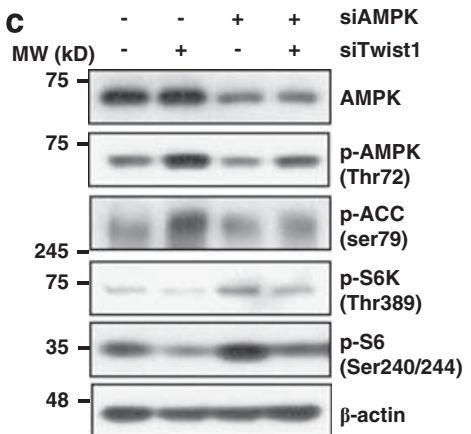

Figure 6 Knockdown of Twist1 induces mTOR activity inhibition through AMPK. (a and b) H1299 and A549 cells were transfected with control, Twist1 or Mcl-1 siRNA for $48 \mathrm{~h}$. ADP/ATP ratios were determined using the Enzylight ADP/ATP ratio assay kit (a). Data are expressed as mean of three independent experiments values and error bars reflect S.D. (c) H1299 cells were transfected with control, Twist1 or AMPK $\alpha 1 / 2$ siRNA for $48 \mathrm{~h}$. The indicated protein levels were measured using western blot analysis (b and $\mathbf{c}$ ) and blots shown are representative of two independent experiments

These results strongly suggest that dysregulation of translation machinery factors is involved in $\mathrm{Mcl}-1$ downregulation by Twist1 siRNA.

In this regard, we determined whether mTOR and its downstream factors are involved in sensitization to cisplatin induced by Twist1 knockdown. Unexpectedly, knockdown of Twist1 led to reduced phosphorylation levels of $\mathrm{mTOR}$ and S6K1, an mTOR downstream effecter. Downregulation of mTOR and S6K1 with siRNA sensitized cells to cisplatin, consistent with the previous finding that transfection of cisplatin-resistant lung cancer cells with siRNA directed against mTOR restores sensitivity. ${ }^{25}$ Importantly, we showed that knockdown of mTOR or S6K1 downregulates the Mcl-1 protein level, which is increased in cisplatin-resistant cells. ${ }^{26}$ These results indicate that $\mathrm{Mcl}-1$ is a downstream target of mTOR and S6K1. Furthermore, Mcl-1 may be regulated at the translational level, because the main function of mTOR is to control translation via direct regulation of S6K1 and 4E-BP. This assumption is supported by several lines of evidence showing that $\mathrm{Mcl}-1$ is a potential downstream target of elF4E that specifically contains a G + C-rich (>70\%) $5^{\prime}$ untranslated region among the antiapoptotic $\mathrm{Bcl}-2$ members. ${ }^{19,27,28}$ In addition, inhibition of mTOR with rapamycin blocked $\mathrm{Mcl}-1$ protein synthesis, but not that of $\mathrm{Bcl}-2$ or $\mathrm{Bcl}-\mathrm{xL} .{ }^{19}$

Surprisingly, knockdown of Twist 1 led to a marked increase in the ADP/ATP ratio, indicating a decrease in ATP content. AMPK is a central cellular energy-sensing system that actively participates in the interaction between metabolism and cancer via regulation of the mTOR pathway. AMPK activation directly phosphorylates and activates TSC2 by enhancing its GAP activity, leading to inhibition of mTOR signaling. ${ }^{29}$ Our findings confirmed that knockdown of Twist1 led to AMPK activation and consequently to mTOR inhibition. Downregulation of AMPK using AMPK $\alpha 1 / 2$ siRNA counteracted the inhibition of mTOR activity by Twist1 siRNA. In the present study, we showed that silencing of Twist1 is associated with ATP depletion, leading to AMPK-activated mTOR inhibition, highlighting a novel underlying mechanism of linking between the Twist 1 and mTOR pathways. However, further research is necessary to clarify the precise mechanisms linking knockdown of Twist 1 to ATP-depletion-induced AMPK activation.

Several studies have reported that increased p21 Waf1/CIP1 expression is associated with tumor progression and negative prognosis and is related to drug resistance in several tumor types. ${ }^{30,31}$ Our experiments revealed that cisplatin or silencing of Twist 1 upregulates $\mathrm{p} 21^{\text {Waf } 1 / \mathrm{CIP} 1}$ expression at the transcriptional level. This $\mathrm{p} 21^{\mathrm{Waf} 1 / \mathrm{CIP} 1}$ upregulation was observed in p53-defective $\mathrm{H} 1299$ cells, and may thus be independent of p53. Treatment of cells with p21 Waf1/CIP1 siRNA enhanced the sensitizing effect of Twist 1 silencing on cisplatin-induced cell death. These results indicate that upregulation of $\mathrm{p} 21^{\mathrm{Waf} 1 / \mathrm{ClP} 1}$ has a protective role against cisplatin or/and Twist1 knockdown-induced cell death, supporting the utility of $\mathrm{p} 21^{\text {Waf1/CIP1 }}$ as a possible therapeutic target, at least for cisplatin treatment, in NSCLC.

In conclusion, we have demonstrated that silencing of Twist1 sensitizes lung cancer cells to cisplatin. This sensitization is mediated by ATP depletion, resulting in AMPK activation and mTOR/S6K1 inhibition, and culminating in downregulation of the Mcl-1 protein level. Our findings highlight a novel mechanism of sensitization to cisplatininduced cell death linking Twist1 to the mTOR pathway and provide a rationale for the use of Twist1 as a promising therapeutic target in lung cancer treatment. 
a
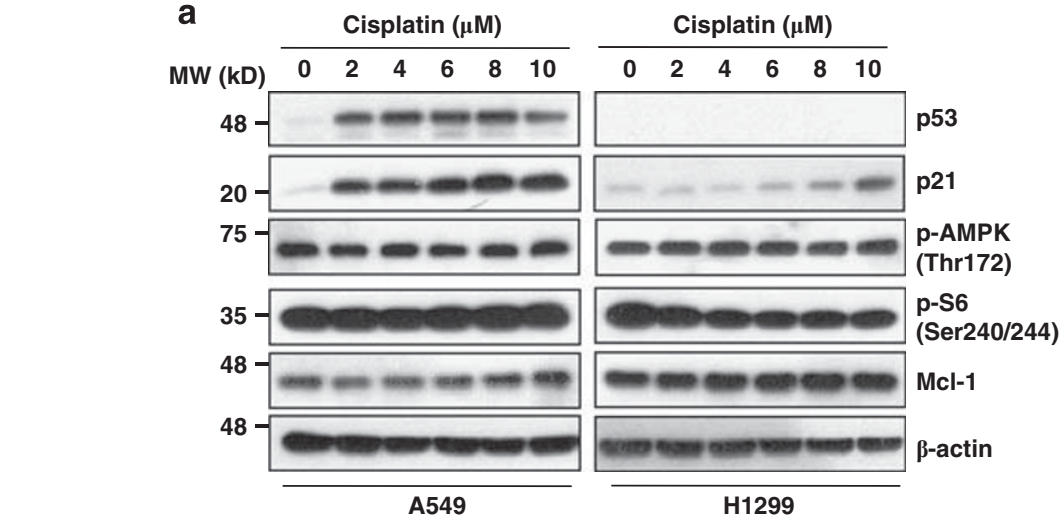

b

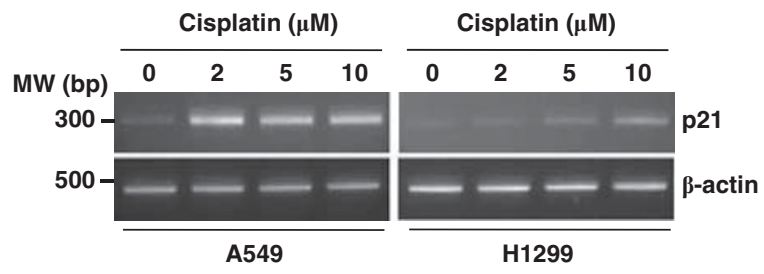

c

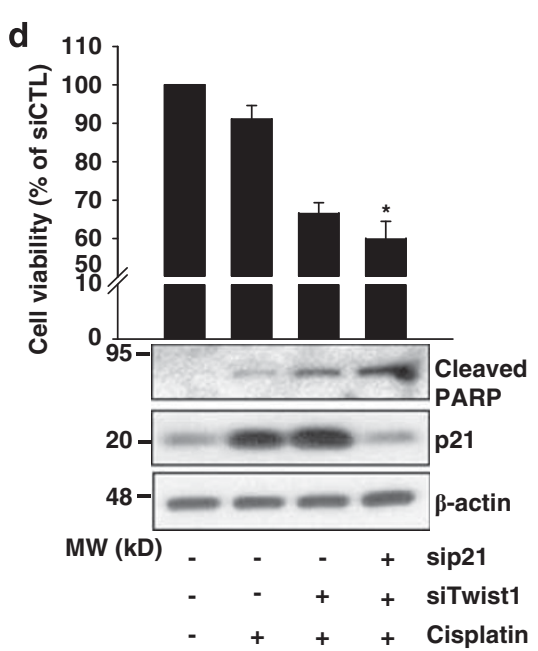

Figure 7 Knockdown of $\mathrm{p} 21^{\text {Waf1/CIP1 } 1}$ promotes the cell death response to cisplatin and Twist1 siRNA. (a and $\left.\mathbf{b}\right) \mathrm{A} 549$ and $\mathrm{H} 1299$ cells were treated with the indicated concentrations of cisplatin for $24 \mathrm{~h}$. (c) A549 and H1299 cells were transfected with control or Twist1 siRNA for $48 \mathrm{~h}$. (d) A549 cells were transfected with control, Twist1 or p21 ${ }^{\text {Waf1/CIP1 }}$ siRNA for $24 \mathrm{~h}$, followed by treatment with $6 \mu \mathrm{M}$ cisplatin for $24 \mathrm{~h}$. The indicated protein and mRNA levels were measured using western blot (a, $\mathbf{c}$ and $\left.\mathbf{d}\right)$ and RT-PCR ( $\mathbf{b}$ and $\mathbf{c}$ ) analyses. Cell viability was measured with the MTT assay (d). Cell viability of control siRNA (siCTL)-treated group was set at $100 \%$, and survival relative to the siCTL presented. The graph is shown as the mean of each group and error bars reflect S.D. ${ }^{*} P<0.05$ versus the siTwist $1 /$ cisplatin-treated group

\section{Materials and Methods}

Cell cultures and reagents. H1299 and A549 cell lines were obtained from the American Type Culture Collection (Manassas, VA, USA) and cultured in the recommended growth medium (Invitrogen, Carlsbad, CA, USA) under $5 \% \mathrm{CO}_{2}$ at $37^{\circ} \mathrm{C}$. cis-Diammineplatinum (II) dichloride was purchased from Sigma-Aldrich (St. Louis, MO, USA).

Measurement of cell viability. Cell viability was determined by measuring the mitochondrial conversion of 3-(4,5-dimethylthiazolyl-2)-2,5-diphenyltetrazolium bromide (MTT) to a colored product. Following treatment of cells with drugs, the MTT reagent was added. Next, cells were solubilized in DMSO. The amount of converted MTT was determined by measuring absorbance at $570 \mathrm{~nm}$.

RT-PCR analysis. Total RNA isolation and CDNA synthesis were conducted, as described previously. ${ }^{32}$ The following primers were used: Twist1 (5'-TGTCCG CGTCCCACTAGC-3' and 5'-TGTCCATTTTCTCCTTCTCTGGA-3', 93 bp product),
Mcl-1 (5'-TGCTGGAGTTGGTCGGGGAA-3' and 5'-TCGTAAGGTCTCCAG CGCCT- $3^{\prime}, 212$ bp product), ${ }^{33}$ p21 $1^{\text {Waf1/CIP1 } 1}$ (5'-ATGGAACTTCGACTTTGTCAC- $3^{\prime}$ and $5^{\prime}$-AGAAATCTGTCATGCTGGTCT-3', $308 \mathrm{bp}$ product) and $\beta$-actin (5'-GGAT TCCTATGTGGGCGACGA-3' and 5'-CGCTCGGTGAGGATCTTCATG-3' $438 \mathrm{bp}$ product).

Plasmids and siRNAs. Full-length Mcl-1 cDNA was cloned into the BamHI/ $X$ bal sites of pcDNA4 HisMax C (Invitrogen) encoding His. S6K1 cDNA containing an N-terminal Myc (plasmid 26610) was purchased from Addgene (Cambridge, MA, USA). All constructs were verified by DNA sequencing.

Twist1 (no. 1, sc-38604), Mcl-1 (sc-35877), AMPK $\alpha 1 / 2$ (sc-45312), p21 (sc-29427) and control (no. 1, sc-37007) siRNAs were purchased from Santa Cruz Biotechnology (Santa Cruz, CA, USA), Twist1 (no. 2, s14523) and control (no. 2, 4611) siRNAs from Ambion (Austin, TX, USA), S6K1 (Hs_RPS6KB1_5) and control (1022076) siRNAs from Qiagen (Valencia, CA, USA) and mTOR (6381) and control (6568) siRNAs from Cell Signaling Technology (Beverly, MA, USA). 
Transfection experiments with plasmids and siRNAs were performed using Lipofectamine Plus and Lipofectamine 2000, respectively, according to the manufacturer's instructions (Invitrogen).

Colony-formation assay. H1299 cells were transfected with Twist1 or Mcl-1 siRNAs for $24 \mathrm{~h}$. Cells were reseeded in $60-\mathrm{mm}$ plates. Colony formation was monitored over the subsequent 10 days. Colonies were stained using the Diff-Quick kit (Sysmex, Hyogo, Japan).

ADP/ATP ratio assay. ADP/ATP ratios were determined using the Enzylight ADP/ATP ratio assay kit (BioAssay, Hayward, CA, USA), according to the manufacturer's instructions.

Western blot analysis. Cell lysates and immunoprecipitates were separated by SDS-PAGE and transferred to nitrocellulose membranes, followed by immunoblotting with the specified primary antibodies and horseradish peroxidase-conjugated secondary antibodies. Immunoreactive bands were visualized with SuperSignal West Pico Chemiluminescent Substrates (Thermo Scientific Pierce, Rockford, IL, USA).

The following antibodies were used: p-AMPK $\alpha$ at Thr172 (2535), AMPK $\alpha$ (2532), p-ACC at Ser79 (3661) and Bcl-2 (2876) p-ERK at Thr202/Tyr204 (9101), p-mTOR at Ser2448 (2971), mTOR (2972) and p-S6K at Thr389 (9205), S6K (9202) and p-S6 at Ser240/244 (4838), S6 (2217), cleaved PARP (9541) and p-AKT at Ser473 (9271) and AKT (9272), AKT2 (2964), Survivin (2808), $\alpha$-Catenin (3236) and $\beta$-Catenin (9562) obtained from Cell Signaling Technology, Vimentin (550513), $\mathrm{N}$-cadherin (610921) and Bcl-xL (610746) from BD Biosciences (San Diego, CA, USA), p53 (NCL-p53-D07) form Novocastra (Newcastle, UK), XIAP (610717) from BD Transduction Laboratories (Lexington, KY, USA), Mcl-1 (sc-12756), p21 (sc-397), c-Myc (sc-40) and His (sc-8036) from Santa Cruz Biotechnology and $\beta$-actin (A5316) from Sigma-Aldrich.

\section{Conflict of Interest}

The authors declare no conflict of interest.

Acknowledgements. This work was supported by a grant (A111770) from the Korea Health Technology R\&D Project by the Ministry of Health and Welfare and the National Nuclear R\&D Program and the Basic Science Research Program in the Republic of Korea.

1. Sanders HR, Albitar M. Somatic mutations of signaling genes in non-small-cell lung cancer. Cancer Genet Cytogenet 2010; 203: 7-15.

2. Spira A, Ettinger DS. Multidisciplinary management of lung cancer. N Engl J Med 2009; 360: 1917.

3. Nishio K, Nakamura T, Koh Y, Suzuki T, Fukumoto H, Saijo N. Drug resistance in lung cancer. Curr Opin Oncol 1999; 11: 109-115.

4. Ma XM, Blenis J. Molecular mechanisms of mTOR-mediated translational control. Nat Rev Mol Cell Biol 2009; 10: 307-318.

5. She QB, Halilovic E, Ye Q, Zhen W, Shirasawa S, Sasazuki T et al. 4E-BP1 is a key effector of the oncogenic activation of the AKT and ERK signaling pathways that integrates their function in tumors. Cancer Cell 2010; 18: 39-51.

6. Richter JD, Sonenberg N. Regulation of cap-dependent translation by elF4E inhibitory proteins. Nature 2005; 433: 477-480.

7. Shaw RJ, Cantley LC. Ras, $\mathrm{PI}(3) \mathrm{K}$ and mTOR signalling controls tumour cell growth. Nature 2006; 441: 424-430.

8. Polyak K, Weinberg RA. Transitions between epithelial and mesenchymal states: acquisition of malignant and stem cell traits. Nat Rev Cancer 2009; 9: 265-273.

9. Thiery JP. Epithelial-mesenchymal transitions in tumour progression. Nat Rev Cancer 2002; 2: 442-454.

10. Peinado $H$, Olmeda D, Cano A. Snail, Zeb and bHLH factors in tumour progression: an alliance against the epithelial phenotype? Nat Rev Cancer 2007; 7: 415-428.
11. Yang J, Mani SA, Donaher JL, Ramaswamy S, Itzykson RA, Come $C$ et al. Twist, a master regulator of morphogenesis, plays an essential role in tumor metastasis. Cell 2004; 117: 927-939.

12. Kang Y, Massagué J. Epithelial-mesenchymal transitions: twist in development and metastasis. Cell 2004; 118: 277-279.

13. Wang X, Ling MT, Guan XY, Tsao SW, Cheung HW, Lee DT et al. Identification of a novel function of TWIST, a bHLH protein, in the development of acquired taxol resistance in human cancer cells. Oncogene 2004; 23: 474-482.

14. Nakashima $\mathrm{H}$, Hashimoto $\mathrm{N}$, Aoyama D, Kohnoh $\mathrm{T}$, Sakamoto $\mathrm{K}$, Kusunose $\mathrm{M}$ et al. Involvement of the transcription factor twist in phenotype alteration through epithelialmesenchymal transition in lung cancer cells. Mol Carcinog 2012; 51: 400-410.

15. Li J, Zhou BP. Activation of $\beta$-catenin and Akt pathways by Twist are critical for the maintenance of EMT associated cancer stem cell-like characters. BMC Cancer 2011; 11: 49.

16. Cheng GZ, Zhang W, Wang LH. Regulation of cancer cell survival, migration, and invasion by Twist: AKT2 comes to interplay. Cancer Res 2008; 68: 957-960.

17. Gan Y, Shi C, Inge L, Hibner M, Balducci J, Huang Y. Differential roles of ERK and Akt pathways in regulation of EGFR-mediated signaling and motility in prostate cancer cells. Oncogene 2010; 29: 4947-4958.

18. Zhang H, Guttikonda S, Roberts L, Uziel T, Semizarov D, Elmore SW et al. Mcl-1 is critical for survival in a subgroup of non-small-cell lung cancer cell lines. Oncogene 2011; 30: 1963-1968.

19. Mills JR, Hippo Y, Robert F, Chen SM, Malina A, Lin CJ et al. mTORC1 promotes survival through translational control of Mcl-1. Proc Natl Acad Sci USA 2008; 105: 10853-10858.

20. Chan S. Targeting the mammalian target of rapamycin (mTOR): a new approach to treating cancer. Br J Cancer 2004; 91: 1420-1424.

21. Petroulakis E, Mamane Y, Le Bacquer O, Shahbazian D, Sonenberg N. mTOR signaling: implications for cancer and anticancer therapy. Br J Cancer 2006; 94: 195-199.

22. Koster R, di Pietro A, Timmer-Bosscha H, Gibcus JH, van den Berg A, Suurmeijer AJ et al. Cytoplasmic p21 expression levels determine cisplatin resistance in human testicular cancer. J Clin Invest 2010; 120: 3594-3605.

23. Zhuo WL, Wang Y, Zhuo XL, Zhang YS, Chen ZT. Short interfering RNA directed against TWIST, a novel zinc finger transcription factor, increases A549 cell sensitivity to cisplatin via MAPK/mitochondrial pathway. Biochem Biophys Res Commun 2008; 369: 1098-1102.

24. Nijhawan D, Fang M, Traer E, Zhong Q, Gao W, Du F et al. Elimination of Mcl-1 is required for the initiation of apoptosis following ultraviolet irradiation. Genes Dev 2003; 17: 1475-1486.

25. Wangpaichitr M, Wu C, You M, Kuo MT, Feun L, Lampidis T et al. Inhibition of mTOR restores cisplatin sensitivity through down-regulation of growth and anti-apoptotic proteins. Eur J Pharmacol 2008; 591: 124-127.

26. Chen W, Bai L, Wang X, Xu S, Belinsky SA, Lin Y. Acquired activation of the Akt/ cyclooxygenase-2/Mcl-1 pathway renders lung cancer cells resistant to apoptosis. Mol Pharmacol 2010; 77: 416-423.

27. Wei G, Twomey D, Lamb J, Schlis K, Agarwal J, Stam RW et al. Gene expression-based chemical genomics identifies rapamycin as a modulator of MCL1 and glucocorticoid resistance. Cancer Cell 2006; 10: 331-342.

28. Wendel HG, De Stanchina E, Fridman JS, Malina A, Ray S, Kogan S et al. Survival signalling by Akt and elF4E in oncogenesis and cancer therapy. Nature 2004; 28: 332-337.

29. Inoki K, Corradetti MN, Guan KL. Dysregulation of the TSC-mTOR pathway in human disease. Nat Genet 2005; 37: 19-24.

30. Fan S, Chang JK, Smith ML, Duba D, Fornace AJ Jr, O'Connor PM. Cells lacking CIP1/ WAF1 genes exhibit preferential sensitivity to cisplatin and nitrogen mustard. Oncogene 1997; 14: 2127-2136.

31. Gorospe M, Wang X, Holbrook NJ. Functional role of p21 during the cellular response to stress. Gene Expr 1999; 7: 377-385.

32. Jin HO, Seo SK, Kim YS, Woo SH, Lee KH, Yi JY et al. TXNIP potentiates Redd1-induced mTOR suppression through stabilization of Redd1. Oncogene 2011; 30: 3792-3801.

33. Aichberger KJ, Mayerhofer M, Gleixner KV, Krauth MT, Gruze A, Pickl WF et al. Identification of MCL1 as a novel target in neoplastic mast cells in systemic mastocytosis: inhibition of mast cell survival by MCL1 antisense oligonucleotides and synergism with PKC412. Blood 2007; 109: 3031-3041.

Cell Death and Disease is an open-access journal published by Nature Publishing Group. This work is licensed under the Creative Commons Attribution-NonCommercialShare Alike 3.0 Unported License. To view a copy of this license, visit http://creativecommons.org/licenses/by-nc-sa/3.0/ 